\title{
Modeling the Sedimentology and STRATIGRAPHY OF CONTINENTAL MARGINS
}

By Michael S. Steckler, Donald J.P. Swift, James P. Syvitski, John A. Goff

and Alan W. Niedoroda

\begin{abstract}
A STRATAFORM is the development of numerical models that provide a means of exploring how the multitude of physical processes active at margins create the preserved stratigraphic record. Numerical models allow study of a wider range of conditions than can be observed easily in the field. or scaled within a laboratory. They also provide tools for extracting and interpreting critical information about the preserved stratigraphy.

The STRATAFORM stratigraphic models must be useful for simulating the accumulation of sediment on continental margins over time scales of tens of years up to one million years. Our interests include predicting the stratigraphic and acoustic signature of a margin based on the region's geological history (sea level, tectonics. terrestrial sediment delivery, and other relevant factors). A primary goal is to develop a "multiprocess sedimentation model" to help understand how external forcing and internal dynamics affect a margin's morphology and stratigraphy.
\end{abstract}

\section{Approach}

The stratigraphy of margins results from the interplay between the creation of accommodation space and the filling of it by sediments. Accommodation space is jointly shaped by the relative subsidence (or uplift) of the seafloor and by changes in the morphology of the seafloor. Sediment fills the space as a function of supply rate and transport processes. However, the processes involved in creating stratigraphy are coupled. For example, sediment deposition is controlled by seafloor morphology, and the buildup of sedimen-

Michael S. Steckler. Lamont-Doherty Earth Observatory. Palisades. NY 10964. USA: Donald J.P. Swift. Department of Oceanography, Old Dominion Univernity, Norfolk, VA 23508. USA: James P. Syvitski, Institute of Arctic and Alpine Research, University of Colorado. Boulder. CO 80309, USA: John A. Goff. Institute for Geophysics. The University of Texas, Austin, TX 78759. USA: Alan W. Niedoroda, Woodward Clyde Consultants, Tallahassee. FL 32303, USA. tary deposits in turn modifies the seafloor morphology.

On continental margins, most sediment transport and accumulation of strata occur during infrequent energetic events (i.e., storms, floods). Extrapolating from these individual events that last days up to geological time scales of thousands and millions of years is a difficult undertaking. The multitude of individual events accumulating over geological time scales yields a complex stratigraphy, especially when combined with the constant change in environmental conditions such as sea level. Even the identification of a preserved record depends on the time scale of interest. The 1995 flood (a 30-y return magnitude event) on the Eel shelf (Wheatcroft et al., 1996, this issue) is already partially reworked: its preservation will depend on the subsequent history of storms and bioturbation. The longer 10.000-y record of Holocene accumulation on the shelf will be partially to completely eroded during the next sea-level lowstand.

Stratigraphic models must also span multiple time and space scales and, as with the STRATAFORM seismic data being gathered (Austin et al.. 1996, this issue), comprise a nested suite. These models attempt to account for the occurrence and stratigraphic effect of individual events, the reworking and accumulation of these events into characteristic sediment bodies (facies), and the lateral shifting and stacking of sediment packages (sequences) that build the large-scale stratigraphic record. We term these the "event." "facies." and "sequence" scales in this paper. We also pursue statistical characterization of the seafloor and subsurface reflectors to capture the scales of variability of margins and to better determine the geological identity of seismic surfaces.

\section{Event Deposit Models}

Estimating sediment delivery and deposition at a continental margin involves simulations of sediment transport processes: fluvial delivery, sedimentation under buoyant river plumes, transport and
The multitude of

individual events accumulating over geological time scales yields a complex stratigraphy ... 
. . natural-process

variability to accu-

rately predict the

physical properties of margin deposits . . . deposition via turbidity currents, current and wave erosion and transport, and sediment gravity flows linked to slope instabilities. The resulting sedimentary deposits depend on the environmental conditions at individual margins (e.g., landscape surface, tectonic environment, sea-level fluctuations, climate, and sediment delivery). STRATAFORM sedimentation models must be able to deal with natural-process variability to accurately predict the physical properties of margin deposits. We approach this by using several semi-independent basin-scale models to simulate river discharge, and sediment transport and deposition within the marine environment.

The first model (HYDROTREND) is a climatedriven, drainage-basin simulator that predicts river velocity and discharge, and sediment concentrations of 5 grain sizes (Syvitski and Alcott, 1995) using either meteorological station data or Global Circulation Model calculations. Daily predictions are computed, as influenced by realistic return-periods of river flooding and longer-term climate trends. Application of the model to the temperate Eel River drainage basin provides a test of the model's handling of rare floods brought on by decadal, centennial, or longer climatic events. U.S. Geological Survey observations on the Eel River include decadal storms and the 400-y flood event in 1964. HYDROTREND successfully captures the range in magnitude and return interval of peak discharge events (Fig. 1) and predicts the associated sediment loads.

HYDROTREND provides input for two river discharge models. The first (PLUME) simulates a buoyant river plume generated from a river's discharge over an areal grid. PLUME solves for the two-dimensional sediment distribution and accumulation rate for each grain size. The second model (INFLO) simulates hyperpycnal flow dynamics at river mouths. If sediment concentrations carried by a river create a flow with a density higher than the ambient coastal water, then the plume will descend as a hyperpycnal current. Small- to medium-size rivers such as the Eel River may trigger these marine underflows during larger flood events (Mulder and Syvitski, 1995). INFLO computes the hyperpycnal flow from a balance of frictional and gravity forces. It provides the run-out distance of a flow across the seabed, and the shape and lithology of resultant deposits. Simulations compare well with seismic and core observations of seafloor deposits (Mulder and Syvitski, 1996).

A surge model (SURGE) completes the present suite of sediment delivery models. SURGE analyzes the transition of a debris flow to a turbidity current. The approach includes the influence of both erosion and deposition from surge-type currents. SURGE has tested favorably against observations of the 1979 Nice (Var River) submarine slide, including the position of sedimentary struc-

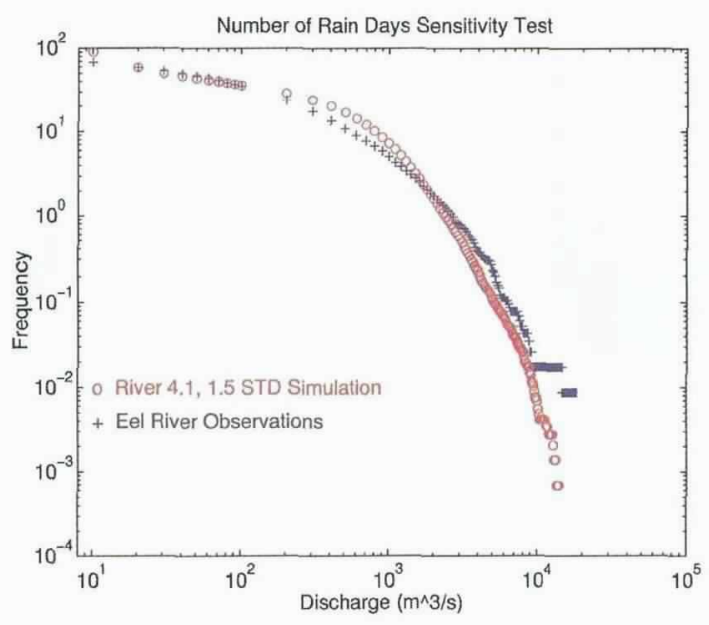

Fig. 1: Return interval frequency for various magnitudes of discharge from the Eel River, northern California. Compared are U.S. Geological Survey observations of measured discharge and HYDROTREND model predictions. The model successfully captures the magnitude and frequency of the 1964 flood, which has a 400-y return interval.

tures, erosion features, and extent of the resultant sand deposit (Mulder et al., 1996).

\section{Facies Development Models}

Individual events are basic building blocks of stratigraphy, contributing, either through deposition or erosion, toward the creation of new beds and preservation of preceding beds. Two problems facing stratigraphic modelers are capturing the complex mix of small-scale, deterministic and chaotic-deterministic processes that build sedimentary deposits, and generalizing these insights to stratigraphically significant time and space scales.

To deal with the stochastic nature of the eventbed succession, we decouple the process of eventbed formation into two components, event-bed generation and event-bed preservation. An event bed forms at the seafloor as a response to a storm or a river flood. With the use of a stochastic storm-generation algorithm, the erosion depth, bed thickness, net accumulation, and mean grain size of each storm bed is computed. A river plume model is used to simulate Eel River flood deposition. The probability of event-bed generation, the bed-generation potential, is determined by the probability density distribution of storms and floods, respectively.

The preserved bed sequence is a biased record of the event series. The initial event bed may be completely destroyed, partly modified, or entirely preserved by subsequent events. A flood bed usually enhances the preservation of underlying beds because it covers them. A storm creates a storm bed but can also destroy or modify underlying beds. The degree of storm erosion depends on both storm power and on the previous history of 


\section{Synthetic Storm Bed Sequence}

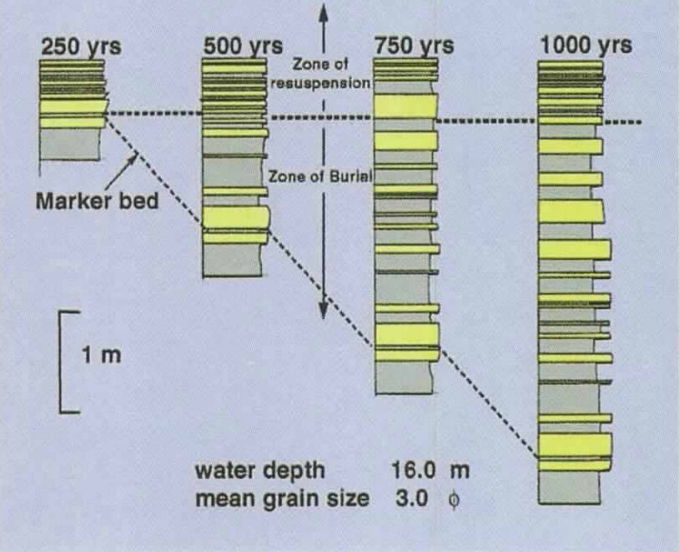

Fig. 2: Growth of a synthetic-event stratigraphic column through successive storm events. Note ephemeral stratigraphy in the zone of resuspension; thin short-return-period beds are reworked by subsequent events before they can pass into the zone of permanent burial.

events. The bed preservation potential describes the probability that an event layer will be buried. Our one-dimensional model (BED) builds event stratigraphic columns by selecting successive storm events from probability density functions describing wave, current, and flooding regimes (Fig. 2) (see Niedoroda et al., 1989; Thorne et al., 1991). By estimating preservation potentials across the continental shelf, the most probable event-bed sequence may be predicted for various water depths.

The BED model is then linked into two-dimensional cross-sections, through which multiple grain-size classes of sediment undergo differential transport during successive events. The coarsest particles introduced during each event tend to be sequestered in the sole of the event bed; erosion during the next event preferentially transports the finer-grained sediment downstream. Progressive sorting results, so that stratification and grain size, two critical facies parameters, vary systematically from proximal to distal stations. Our facies model (SHELF) then predicts the preserved bed sequences in terms of the bed preservation potentials. The modeled bed sequences across the shelf are characterized by four facies parameters (Fig. 3 ), giving a high-resolution, process-oriented, and quantitative description of the stratigraphy.

As the depositional system accumulates sediment, the distribution of facies varies with the rate of sea-level change, rate of sediment input, sediment grain-size distribution, and the sediment transport functions (climate). The depositional en- vironments move through space as these quantities vary, and facies bodies are generated across the shelf. Movement of the depositional environments along the margin can cut erosional unconformities as well as build deposits.

To examine facies patterns across both the shelf and slope of a margin, we have developed a pair of programs (Fig. 4). The DELTA6 sedimentation model (Syvitski and Alcott, 1995) includes five mechanisms that affect the rate and style of basin-filling: 1) hemipelagic sedimentation by river plumes, 2) bedload deposition at the river mouth, 3) delta-front failures and consequent turbidity currents, 4) downslope diffusive processes that smear previously deposited sediment, and 5) slope failures and downslope mass movement due to the buildup of excess pore pressure. FACIES provides a graphical interface to track offshore deposits and properties.

\section{Sequence Stratigraphic Models}

At larger time scales, relative subsidence and uplift of the seafloor is increasingly important in determining the sites of sediment accumulation. We have created a model (SEQUENCE) that combines a long-term sedimentation module with a
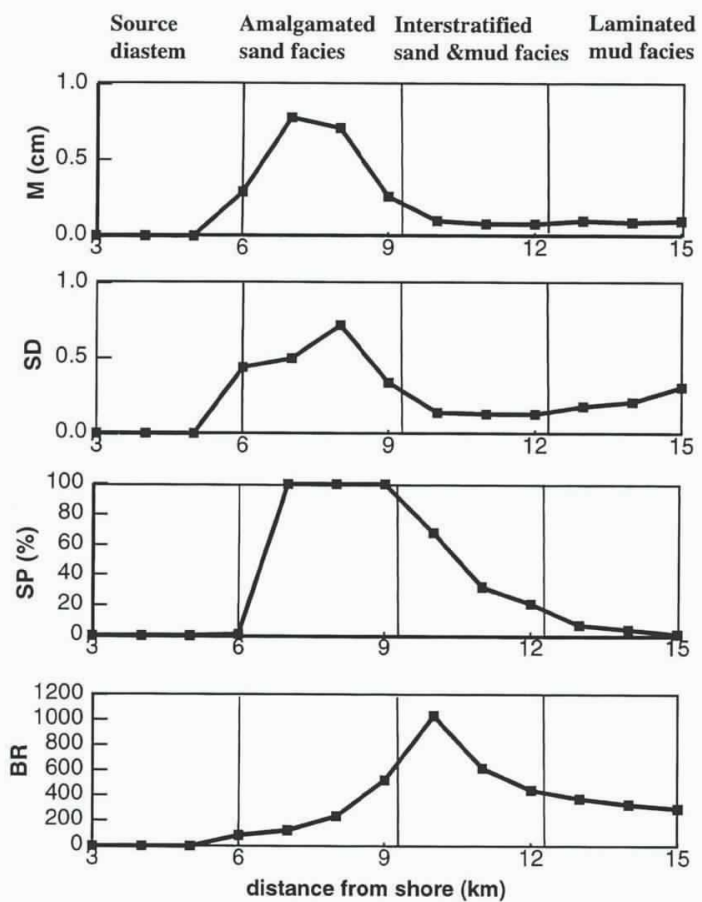

Fig. 3: Predicted facies variation across continental margin from probabilistic event model. The four plots show changes in mean bed thickness $(M)$, standard deviation of bed thickness (SD), sand-bed percentage (SP), and bed rhythmicity (BR) across the shelf. The patterns of these four parameters group into the four facies noted at the top.
... the most proba-

ble event-bed sequence may be predicted for various water depths. 


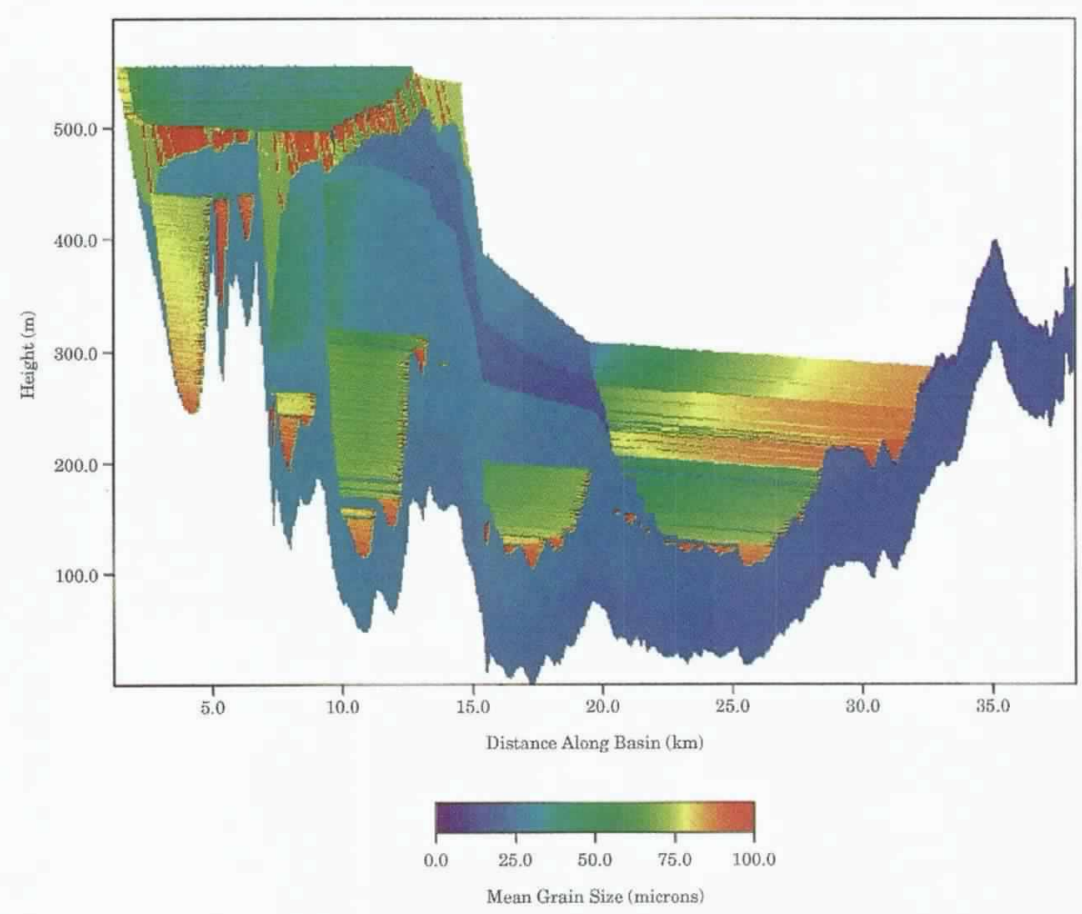

Fig. 4: Example of a FACIES model run. The time step is 1 day; the total period was 5,000 y. Colors represent the mean grain size as indicated. A slow linear sea level lowering was used during the first 2,000 y with a high sediment yield from the hinterland. Sea-level recovered for the next 2,000 y during a time of greatly reduced sediment yield. The simulation is completed with an exponential sea level lowering concomitant with high sediment loads. The result is a net seaward movement of the shore. Shoreline deposits are mainly preserved from the progradational parts of the simulation.

\section{As sea level rises}

or falls, the margin

profile translates

landward or seaward

dynamically . . . are enhanced for different parts of the shelf, yielding characteristic stratal patterns.

The geophysical framework includes major factors that affect accommodation space: tectonics and eustasy, flexural (regional) isostatic compensation of the sediment and water loads, and compaction. The latter two processes can significantly modify the space made available and thus provide feedbacks between tectonic and depositional processes (Steckler et al., 1993).

The STRATAFORM stratigraphic models must handle time scales of $10^{3}-10^{6}$ years. At shorter time scales $\left(10^{3}-10^{4} \mathrm{y}\right)$, compaction and isostatic compensation cannot be considered instantaneous. Isostatic adjustment to the last deglaciation is still ongoing, for example. Therefore, time-dependent isostatic adjustment to sediment and water loads has recently been incorporated into the model. Compaction is a major source of subsidence in older continental margins, especially for large deltas (Milliman and Haq, 1996). The rate of compaction-induced subsidence depends on the sediment accumulation rate, and porosity and permeability of the underlying sediments. Adjustment to deposition can vary from nearly instantaneous to delays of millions of years. Time-dependent sediment compaction will be implemented in SEQUENCE. These lags in adjustment to sediment loads will alter the stratigraphic signature of sealevel change.

\section{Statistical Models}

In the study of actual continental margins, data are always limited. For example, the bathymetry of a continental shelf may be known, but only a limited number of seismic-reflection profiles across the region exist. In many circumstances, we may wish to predict the stratal architecture everywhere within the region based on this subset. Such modeling is termed "conditional simulation" (e.g., Journel and Huijbregts, 1978). Unlike the modeling discussed earlier, conditional simulation is entirely driven by morphology rather than by physical processes.

In constructing successive surfaces, the modeling must honor: 1) deterministic data constraints (e.g., bathymetry, seismic reflection data), 2) statistical characterization of the stratal surfaces (e.g., spectral and probability density functions), and 3) constraints from nearby simulated surfaces, which may be provided through a description of the coherence among stratal boundaries as a function of scale. The deterministic data are hard constraints, dictating the functional value at a particular location. Statistical characterizations tell us what the roughness properties of each surface must be. Coherence among stratal surfaces tells us to what degree and over what scales two surfaces must be alike, and conversely how they can differ.

One test of our ability to predict subsurface stratal architecture and sediment properties is a 
comparison of the predictions of the stratigraphic models described earlier and conditional simulation models. Conditional simulation predicts properties of subsurface reflectors, calibrating to observed properties of the seafloor. In contrast, stratigraphic models attempt to interpret subsurface properties through process models that simulate the conditions that created the surfaces. If the formation of the stratigraphy is understood and we can predict the physical properties of the subsurface, then both sets of predictions should agree. Cores can then sample specific locations to assess the accuracy of both methods. Convergence of these two distinct approaches over the entire margin will test our understanding of the margin at depth and highlight areas for further study.

\section{Summary and Future Plans}

Our goal is a quantitative understanding of the interactions of environmental parameters and their contribution to the observed stratigraphic record. Event, facies development, and sequence stratigraphic models must be formulated in terms of the sediment and lithospheric dynamics that underlie the observed behavior. We have developed an initial suite of models. Now, each must be further improved to fully capture the processes that form stratigraphy at margins. The coupling between the models must also be expanded. For example, the rate and direction of sea-level change should be combined with hinterland climate and landscape models to better estimate the dynamics of river plumes, and thus the accumulation rate and physical properties of sediment units during eustatic cycles. Predicted margin architecture from sequence models will be used as input to facies models to provide greater detail in filling the margin with sediment properties and facies.

Continental-margin stratigraphy is inherently three-dimensional. River plumes spread and are deflected by alongshelf currents (Wheatcroft $e t$ al., 1996, this issue). Rivers, slope canyons and gullies, and other features are channelized. The shelf morphology has undulations at a wide variety of scales (e.g., ripples, sand waves, sand ridges) that interact with depositional/erosional processes (Goff et al., 1996, this issue). Stratigraphic modeling also must be three-dimensional to be successful. Some of the models described above are three-dimensional, whereas others work only in profile. During STRATAFORM we will be developing three-dimensional process models and stratigraphic models. We have begun with two-dimensional models in order to understand the physics of stratigraphy formation, and because of the computational overhead of three-dimensional models. By the end of STRATAFORM, models will be implemented in three dimensions or at least in profile with some three-dimensional effects.

The suite of models that are being developed must form a coherent, self-consistent whole. They

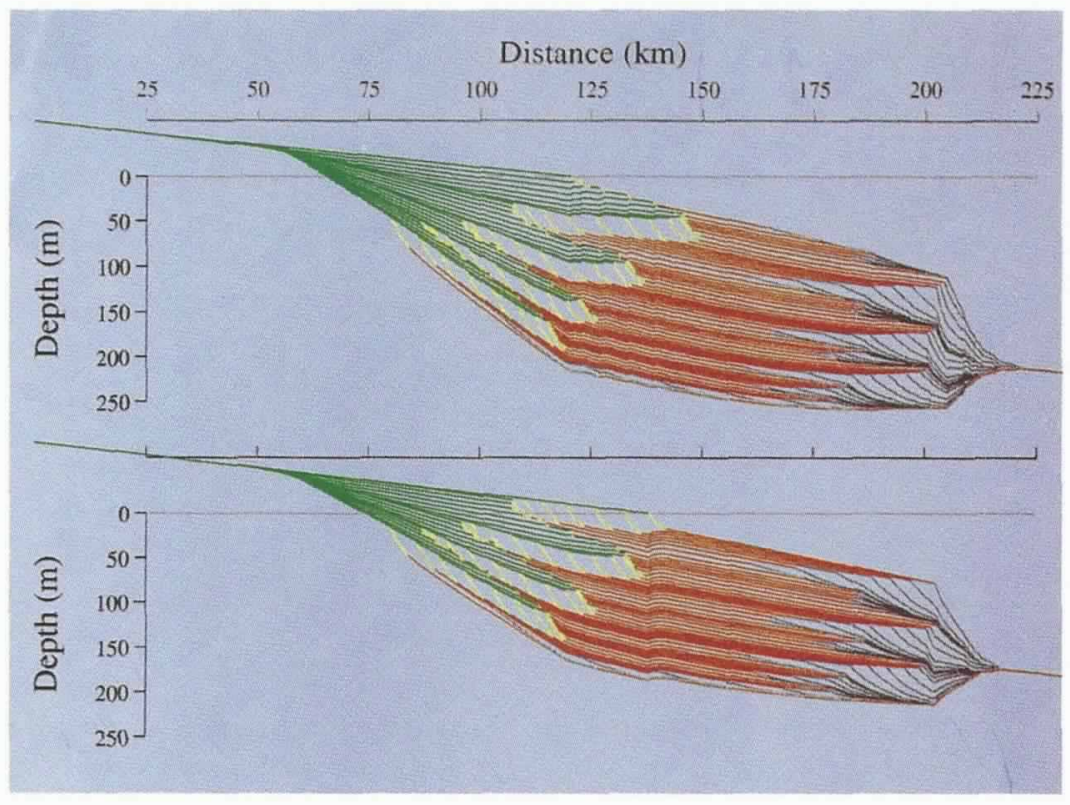

Fig. 5: Images of two time steps from a SEQUENCE model run. The simulation was run with a 100-Ky period sinusoidal sea level with an overall longterm fall, resulting in the net seaward movement of the shore. There are 16 timelines per sea-level cycle. Green: nonmarine sediments; yellow: shoreface sediments; magenta: marine shelf sediments. The shoreline deposits are mainly preserved from the progradational parts of the sequences. Note the difference in the slope near the shoreface for the transgressive (top) and regressive (bottom) parts of the cycle.

must also be calibrated at all scales from appropriate data suites, tested in field areas, and studied to understand the dynamics of the multiscale system. Data from the field areas and elsewhere must be used to calibrate model parameters and ensure accuracy of predictions. Each model, as it is further developed, must be used for extensive numerical experimentation to understand its properties and how the controlling parameters interact and affect results. Specific modeling of the two STRATAFORM field areas will provide extensive tests of the models and provide insight into how the stratigraphy of these two distinct environments is created. By the end of STRATAFORM, our aim is to have a system of models that can be used to understand stratigraphy formation, and how external factors determine stratigraphic architecture and sediment properties. Then these models can become a predictive tool to calculate the stratigraphy and sediment properties of other margins, and to interpret the conditions that produced them.

\section{Acknowledgments}

We thank Bob Courtney, Ann Esmay, Murray Nicholson, Mark Morehead, Chris Reed, Ken Skene, and Yong Zhang for their help in modeling efforts. This paper was improved by reviews from Jamie Austin, Chuck Nittrouer, and Joe Kravitz. Our thanks to Joe Kravitz, Chuck Nittrouer, and our aim is to

have a system of

models that can be

used to understand

stratigraphy forma-

tion . 
the STRATAFORM program for valuable discussions. This work was supported by grants from the Office of Naval Research. Lamont-Doherty Earth Observatory Contribution 5560.

\section{References}

Austin, J.A.. C.S. Fulthorpe, G.S. Mountain, D.L. Orange and M.E. Field. 1996: Continental-margin seismic stratigraphy: assessing the preservation potential of heterogeneous geological processes operating on continental shelves and slopes. Oceanography, 9, 173-177.

Goff, J.A., L.A. Mayer, J. Hughes-Clarke and L.F. Pratson, 1996: Swath mapping on the continental shelf and slope: the Eel River Basin, northern California. Oceanography, 9, 178-182.

Journel, A.G. and C.J. Huijbregts, 1978: Mining Geostatistics, Academic Press, New York.

Milliman, J.D. and B.U. Haq, 1996: Sea-Level Rise and Coastal Subsidence: Causes, Consequences, and Strategies. Kluwer Academic Publishers, Dordrecht, Netherlands, $369 \mathrm{pp}$.

Mulder, T., B. Savoye and J.P.M. Syvitski, 1996: Numerical modelling of the sediment budget for a mid-sized gravity flow: the 1979 Nice turbidity current. Sedimentology. In press.

and J.P.M. Syvitski, 1995: Turbidity currents generated at river mouths during exceptional discharge to the world oceans. J. Geol., 103, 285-298.

and J.P.M. Syvitski. 1996: Modelling of erosion and deposition by sediment gravity flows generated at river mouths. J. Sed. Res. In press.
Niedoroda, A.W., C.W. Reed, D.J.P. Swift, A. Arato and K. Hoyanagi, 1995: Modeling shore-normal large scale coastal Evolution. Mar. Geol., 126, 180-200.

D.J.P. Swift and J.A. Thorne, 1989: Modelling shelf storm beds: controls of bed thickness and bedding sequence. In: Shelf Sedimentation. Shelf Sequences and Related Hydrocarbon Accumulation. R.A. Morton and D. Nummedal, eds. Gulf Coast Section, Soc. Econ. Paleon. and Mineral., Seventh Annual Research Conference Proceedings, 15-39.

Steckler, M.S., D.J. Reynolds, B.J. Coakley, B.A. Swift and R.D. Jarrard, 1993: Modeling passive margin sequence stratigraphy. In: Sequence Stratigraphy and Facies Associations. Intern. Assoc. Sediment. Spec. Pub. 18. H.W. Posamentier, C.P. Summerhayes, B.U. Haq and G.P. Allen, eds. 19-41.

Syvitski, J.P.M. and J.M. Alcott, 1995: DELTA6: numerical simulation of basin sedimentation affected by slope failure and debris flow runout. In: Pierre Beghin International Workshop on Rapid Gravitational Mass Movements, Grenoble, France, 305-312.

Thorne, J.A., E. Grace, D.J.P. Swift and A.W. Niedoroda, 1991: Sedimentation on continental shelves, part III. The depositional fabric: an analytical approach to stratification and facies. In: Shelf Sand and Sandstone Types: Geometry, Facies and Distribution. D.J.P. Swift, R.A.W. Hillman and G.O. Oertel, eds. Int. Assoc. Sediment. Spec. Paper 14.

Wheatcroft, R.A., J.C. Borgeld, R.S. Born, D.E. Drake, E.L. Leithold. C.A. Nittrouer and C.K. Sommerfield. 1996: The anatomy of an oceanic flood deposit. Oceanography, 9, 158-162. 